\title{
ACESSO A JUSTIÇA E A INCOMPATIBILIDADE DOS PRINCÍPIOS ADMINISTRATIVOS COM AS NORMAS DOS JUIZADOS DA FAZENDA PUBLICA.
}

\author{
Taís Dórea de Carvalho Santos ${ }^{1}$
}

RESUMO: Este artigo tem como objetivo analisar os Juizados da Fazenda Pública criados pela Lei $\mathrm{n}^{0} 12.153 / 2009$, sob o prisma do acesso a justiça. Numa breve analise dos princípios norteadores destes Juizados se verifica a incongruência com os princípios pertinentes a Administração Publica, principalmente a legalidade e impessoalidade. Desta forma resta comprometido o acesso a justiça uma vez que a aplicação das regras que trariam uma maior efetivação a este principio acabam por não ter qualquer aplicação nas lides que envolvem a Fazenda Pública, que possuem restrições nos seus princípios constitucionais constantes no art. 37 da CRFB.

Palavras-chave: Acesso a Justiça; Juizados; Fazenda Pública; Legalidade; Impessoalidade.

\section{ACCESS TO JUSTICE AND THE INCOMPATIBILITY OF THE ADMINISTRATIVE PRINCIPLES WITH THE RULES OF THE JUDGES OF THE PUBLIC FUND.}

\begin{abstract}
This article aims to analyze the Public Finance Courts created by Law 12.153 / 2009, under the prism of access to justice. In a brief analysis of the guiding principles of these Courts there is an inconsistency with the principles pertinent to Public Administration, mainly legality and impersonality. In this way, access to justice is compromised since the application of the rules that would bring greater effectiveness to this principle end up not having any application in the cases involving the Public Treasury, which have restrictions in their constitutional principles in art. 37 of the CRFB.
\end{abstract}

Key Words: Access to Justice; Judges; Public farm; Legality; Impersonality.

\section{INTRODUÇÃO}

Os princípios são a base normatiza do ordenamento jurídico brasileiro. Por tal razão, não há de se falar em regras que fujam do propósito a que elas se prestam, que é, justamente,

\footnotetext{
${ }^{1}$ Doutoranda em Políticas Sociais e Cidadania pela Universidade Católica de Salvador. Mestra em Direito Público pela Universidade Federal da Bahia. Especialista em Metodologia do Ensino Superior pela Faculdade Olga Mettig. Graduação em Direito (Estácio/FIB) e Comunicação Social (UNIFACS). Advogada e professora universitária.
} 
trazer os princípios de forma mais próxima da concretude. Portanto, as leis são tentativas de concretização dos princípios.

Assim, leis são criadas com o intuito de aproximar os princípios as diversas realidades, traduzindo-os em regramentos mais acessíveis e concretos. Então as leis são, na verdade, complementações dos princípios e precisam, de fato, fazer com que estes sejam efetivados e não afastá-los.

A norma existe com a finalidade maior de realizar os valores compreendidos como importantes na sociedade, bem como os que precisam de tutela. Esses valores então são transformados em dispositivos, fontes de realização do direito e justiça. Estes direitos, inclusive, são os imprescindíveis para a garantia de cidadania - que é um fundamento do Estado brasileiro previsto no art. $1^{\circ}$, II da Constituição da República.

O principio do acesso a justiça, trazido no primeiro tópico do artigo, deveria se prestar a este fim, qual seja, como garantia de cidadania e possibilidade de recorrer a órgão jurisdicional quando houve lesão ou ameaça de direito, conforme prevê o art. 5, XXXV da CRFB. Algumas observações serão feitas no primeiro tópico sobre este principio compreendendo-o no contexto constitucional brasileiro.

A análise rasa desde princípio relaciona-se a entendê-lo apenas na sua perspectiva formal, como a possibilidade de ter tutela atendida através da possibilidade de ação judicial. Aqui se entende o acesso a justiça por seu aspecto amplo não tratando apenas de um acesso a justiça formal, mas, principalmente, material, quando não afasta a apreciação concreta do poder judiciário.

A situação brasileira abre uma série de discussões sobre o tema. Isto porque o problema do acesso a justiça é mais profundo e está intimamente ligado a inoperância estatal como um todo. O sistema judiciário tem uma série de dificultadores que acabam por trazer a tona elementos que afastam a possibilidade de decisão justa, tempo razoável e, muitas vezes do simples acesso formal.

O Estado vem buscando formas de garantir prestação jurisdicional eficiente e formas de solucionar os problemas de superlotação do judiciário. Uma dessas possibilidades é a criação de juizados especiais que teriam a função de simplificar o andamento de ações de baixa complexidade, tornando esta prestação jurisdicional mais célere, e, como dito na exposição de motivos da lei 9.099/1995, menos burocrático.

Então foram criados Juizados Especiais que prestariam um serviço mais célere para casos menos complexos, garantido uma tutela jurisdicional mais assertiva e com maior 
participação das partes. Isto se torna possível porque a natureza não complexa da lide, e é fato que facilita e garante uma tutela mais célere sem prejuízo ao principio do acesso à justiça, beneficiando as partes.

Em relação a Fazenda pública, que tem principio específicos, tratados no segundo tópico deste artigo, a fim de tornar as tutelas mais céleres, o poder legislativo entendeu por estender, criando os Juizados Especiais da Fazenda Pública. Para tanto, utilizaram como base a lei n 9099/95, que tem como ponto de partida os critérios da oralidade, simplicidade, informalidade, economia processual, celeridade e a busca da conciliação ou a transação, como previsto no se art. 2.

Observando o previsto na lei 12.153/2009, que dispõe sobre os Juizados Especiais da Fazenda Pública no âmbito dos Estados, do Distrito Federal, dos Territórios e dos Municípios, resta claro que trata de uma tentativa da aplicação dos preceitos dos juizados especiais para as Fazendas Públicas.

Ocorre que, sob a pretensão de dar celeridade aos processos, acaba por limitar a real analise das situações tuteladas lá. O ultimo tópico tratará de algumas destas incompatibilidades de procedimentos que são estranhos a própria natureza do direito administrativo, como a obrigatoriedade de realização de audiência de conciliação em situação de indisponibilidade do direito.

Assim, a simples aplicação das regras destes juizados, sem a efetiva observância das prerrogativas da Fazenda Pública acaba por afastar o principio do acesso a justiça em vez de aproximá-lo e o cumpri-lo, o que será tratado de maneira breve e pontual.

Este artigo foi realizado em forma de revisão de leitura, analisando os aspectos principiológicos que envolvem o tema e levantando os pontos de incongruência entre a lei que rege os Juizados Especiais da Fazenda Pública e os princípios inerentes a Administração Pública.

\section{PRINCIPIO DO ACESSO A JUSTIÇA E OS JUIZAZOS ESPECIAS}

O Estado Democrático de Direito tem como função principal a realização dos direitos fundamentais e os desejos e anseios sociais, criando mecanismos e instituições que tenham este propósito. Tendo como base normativa a Constituição da República, todo arcabouço legal tem como finalidade maior de realizar os valores compreendidos como importantes na sociedade, bem como os que precisam de tutela. 
Esses valores então são transformados em dispositivos, fontes de realização do direito e justiça. São estes direitos, inclusive, os imprescindíveis para a garantia de cidadania - que é um fundamento do Estado brasileiro previsto no art. $1^{\circ}$, II da Constituição da República.

Como membro integrante da vida política e a construção da própria estrutura jurídica do direito brasileiro, o cidadão tem, ou deveria ter mecanismos para permitir o gozo dos seus direitos fundamentais, além dos deveres de contribuir para a efetivação de uma sociedade mais justa - garantidora destes mesmos direitos.

Estes direitos são de aplicação imediata e vinculante. Uma vez previstos, o Estado tem a função primaz de realizá-los. E esta função é cada vez mais cobrada, principalmente em países com desigualdades sociais como o Brasil. Então, o Estado é convocado a defender estes direitos, mais que isto a os realizar através de políticas públicas, serviços públicos e proteção administrativa e jurisdicional aos demais direitos.

São os direitos fundamentais norteadores da atividade estatal e balizadores das perspectivas políticas dos diversos estados democráticos e que tem os direitos humanos como base jurídica e política. “Os direitos fundamentais constituem os alicerces da relação entre Estado e indivíduos; o exercício do poder político pelo Estado se legitima pela necessidade de preservar os direitos fundamentais” (NETTO, 2010, pág. 37).

\footnotetext{
Princípios são, por conseguinte, mandamentos de otimização, que são caracterizados por poderem ser satisfeitos em graus variados e pelo fato de que a medida devida de sua satisfação não depende somente das possibilidades fáticas, mas também das possibilidades jurídicas. (ALEXY, 2008, p. 90).
}

Portanto, a tutela jurisdicional deve existir com a finalidade da concretização da justiça, através dos procedimentos pertinentes a garantir que os direitos sejam verificados, principalmente os direitos fundamentais. Então o Estado cria mecanismos para efetivação dos direitos fundamentais através de todos os órgãos e poderes existentes. Traduz em princípios e estes em procedimentos e leis.

Como a própria CRFB apresenta em seu bojo, o Estado deve atuar respeitando os princípios pertinentes Administração Pública, dentre eles a eficiência. Esta engloba todos os serviços prestados, incluindo o jurisdicional.

Quando se fala em atuação do judiciário, um dos princípios que saltam os olhos é o do acesso à justiça. A garantia que o individuo tem de que, precisando de tutela judicial, terá garantida a mesma. Mais que isto, o acesso a justiça material, tendo mecanismos que de fato 
possibilitem isso.

A análise rasa desde princípio relaciona-se a entendê-lo apenas na sua perspectiva formal, como a possibilidade de ter tutela atendida através da possibilidade de ação judicial. Mas este princípio vai mais além, trata também do alcance deste direito através de decisão judicial justa e num tempo razoável (SOUZA, 2011, p. 22).

Os princípios pretendidos quando da criação dos juizados especiais cíveis e criminais, quais sejam, oralidade, simplicidade, informalidade, economia processual, celeridade e a busca da conciliação ou a transação, não se compatibilizam com os princípios da administração pública, quais sejam, legalidade, impessoalidade, indisponibilidade do interesse público, por exemplo.

Então, resta claro, que uma simples adequação da lei 9.099/95 com a finalidade de trazer celeridade às ações contra Fazenda Pública, nos termos apresentados na lei 12.153/2009, acabam por comprometer o acesso a justiça material.

O acesso a justiça em situações menos complexa foi facilitada coma criação dos juizados especiais cíveis e criminais. Isto porque se estava diante de demanda simples entre pares e relações consumeristas (juizados cíveis) e contravenções penais (juizados criminais).

Observava-se que os litígios, nestes casos, poderiam ser resolvidos com a mediação, ou seja, o judiciário deixaria a resolução da questão entre as partes preferencialmente, só decidindo se não houvesse conciliação.

Por tal razão se tem como princípios básicos desses juizados a oralidade, simplicidade, informalidade, economia processual, celeridade e a busca da conciliação ou a transação. Note que todos os princípios são ligados diretamente a possibilidade de acordo entre as partes, alcançando a justiça por deliberação das partes que podem, inclusive, dispor de um direito para conciliar.

Assim, trata-se de direitos disponíveis, ou, ao menos, de situações onde exista a flexibilização deste direito. As partes transigem a fim de acharem um meio termo, uma situação que seja interessante para os dois lados.

Outro ponto a se destacar é a informalidade. Ou seja, não exige solenidade nas formas, uma vez que a função destes juizados é a manifestação da vontade das partes e a solução dos conflitos que ali chegam. Para que seja assim garantido, utiliza-se outro principio importante seria o da economia processual, agregando a este instituto possibilidades diversas de resolver o litígio de maneira rápida e simples.

Outro principio que merece destaque é a busca da conciliação ou a transação. Isto quer 
dizer que a preferência é sempre que as partes resolvam o litígio e que somente nos casos onde não se tenha outra opção, o juízo decidiria pela procedência ou improcedência dos pedidos.

Então, como já dito, o Estado serviria mais como um mediador das lides que como julgador delas. O julgamento se daria pelo principio da inafastabilidade jurisdicional, previsto no art. 5, XXXV da CRFB.

\section{OS PRINCIPIOS RELATIVOS À FAZENDA PÚBLICA}

Para melhor compreensão do problema aqui trazido, importante conhecer um pouco da função Administração Pública dos seus princípios basilares, com a finalidade de se observar o próprio sentido do Estado (MELLO, 2006). Tem como normativa predominante a Constituição da República e esta diretamente ligado a obrigatoriedade do Estado em atender os anseios sociais, suas necessidades e finalidades (CANOTILHO, 2003).

A conceitação de Estado esta relacionada diretamente a coisa pública, ou seja, algo que pertence a coletividade. Ele é responsável pela organização social, utilizando de diversos mecanismos e instituições para o melhor desenvolvimento desta coletividade (ROUSSEAU, 1996). Assim, o Estado pode ser definido como o exercício de um poder político, administrativo e jurídico, imposto aos indivíduos que habitam determinado território.

Por ter o Estado o papel primaz organizar a sociedade, deu-se a ele a função de proteção aos direitos individuais diante do Estado e a necessidade de satisfação de interesses públicos (ROCHA, 1994). Para isto, existe a outorga de prerrogativas e privilégios para a Administração Pública que acabam por impossibilitar atuações deste que não sejam previamente autorizadas.

Destaca-se dentre estes o princípio da legalidade, considerado princípio basilar do direito administrativo. O entendimento da legalidade é primordial para qualquer análise do papel da Administração Pública, e com ele a indisponibilidade do Ente Público em agir contrário ao previsto em lei.

O conceito de legalidade para a Administração Pública é um pouco mais enxuto que para as demais pessoas. Isto porque a legalidade esta relacionada a subordinação a lei, não a inexistência de proibição. Acontece por esta diretamente ligada ao principio da finalidade administrativa, sendo valido apenas quando se atende o fim legal (SILVA, 2008)

A legalidade é compreendida incluindo seus aspectos principiológicos, mas não se pode negar que, em regra, tem-se a necessidade de previsões expressas, com diagnósticos 


\section{ACESSO A JUSTIÇA E A INCOMPATIBILIDADE DOS PRINCÍPIOS ADMINISTRATIVOS \\ COM AS NORMAS DOS JUIZADOS DA FAZENDA PUBLICA.}

específicos para situações diversas, existe apenas certa margem de discricionariedade para determinados atos. Portanto, aqui a legalidade se apresenta como a completa subordinação do administrador a lei, engessando assim a própria operacionalização da administração pública (ROCHA, 1994).

Este elemento restritivo da legalidade existe com a intenção de garantir um maior controle pela sociedade, uma menor margem de abuso dos gestores e a segurança jurídica. Então, a sociedade seria quem determinaria o que ela compreende como essencial e importante, através de leis criadas por seus representantes e os gestores teriam possibilidades previamente autorizadas quando da sua atuação.

Já a segurança jurídica é elemento imprescindível para assegurar a ordem social e aplicação das políticas públicas necessárias a fim de conseguir concretizar as demandas sociais representadas pelos direitos fundamentais trazidos no bojo da nossa CRFB. Ela existe como forma de proteção ao individuo contra possíveis arbitrariedades do Estado, ou seja, deve ser observada do ponto de vista do indivíduo e não do Estado (RAMOS, 2012, p. 416).

Então, não se pode aventar a possibilidade da Administração Pública deixar de cumprir o previsto em lei ou dispor disto, não havendo, a principio, qualquer hipótese de transação por parte do Estado em demandas que o envolve.

Ainda que hoje a Administração Pública seja compreendida de uma maneira diferente, assumindo mais responsabilidade, e tendo mais flexibilidade, respeitando sempre a indisponibilidade do interesse público. O dialogo entre o Estado e a própria sociedade se coloca em uma relação cada vez mais profunda.

Num Estado Democrático de Direito a relação entre a Fazenda Pública e a política é indiscutível (BOBBIO, 2008), tendo que, por obvio, obedecer aos desejos sociais (GEERTZ, 2008), necessário para isto, manter um diálogo aberto entre a sociedade e suas instituições.

Portanto, a compreensão da Fazenda Pública, em uma democracia, seria da realização dos direitos em situação dialógica com a sociedade, tendo a participação social como imprescindível para a configuração das instituições que atendem interesses públicos.

Mas não é o que ocorre. O Brasil vive uma relação legalista com a sociedade e não existindo ainda uma alteração principiológica que permita uma maior flexibilização, fugindo da legalidade estrita aqui tratada.

A compreensão de como é e o que deveria ser é fundamental para garantir uma maior eficácia nas instituições que tratam da Fazenda Pública, incluído o sistema jurisdicional que 
esta apto a cuidar das questões relacionadas aos entes públicos, inclusive através de leis que tratam de suas prerrogativas.

Como exemplo básico se tem a obrigatoriedade do reexame necessário. Esta prerrogativa esta associada a sua condição de Estado e representante garantidor da sociedade, não podendo se relacionar com os particulares de igual para igual.

Portanto, as prerrogativas referentes a Fazenda Pública não acontecem por mera liberalidade, mas como forma de garantir a situação peculiar de representação do interesse público que lhe é, particularmente, mais que prerrogativa, uma função social.

\section{A INCOMPATIBILIDADE DOS PRINCIPIOS ADMINISTRATIVOS E AS REGRAS TRAZIDAS NA LEI QUE INSTAURA OS JUIZADOS DA FAZENDA PÚBLICA.}

Os Juizados de Fazenda Pública foram criados pela Lei n 12.153/2009, que possui apenas 28 artigos, estabelecendo as diretrizes básicas para seu funcionamento. Trata basicamente da competência e das partes, bem como das possibilidades pela lei. Não apresenta expressamente os princípios trazidos na lei n 9.099/1995, mas deixa clara a aplicação subsidiaria desta lei, além de insistir, desde o primeiro artigo na conciliação entre as partes.

Apresenta a obrigatoriedade de audiências de conciliação e tem como ponto de partida este instituto, quando deixa claro que é de sua competência processar, conciliar e julgar causas cíveis de interesse dos Estados, do Distrito Federal, dos Territórios e dos Municípios, até o valor de 60 (sessenta) salários mínimos.

O objetivo maior seria, justamente, achar um ponto de equilíbrio entre as partes envolvidas, quais sejam, de um lado o Estado do outro um particular. E a proposta dele é que as partes encontrem um consenso.

Esta previsão da audiência de conciliação com as possibilidades previstas no art. $8^{\circ}$ da lei 12153/2009 é completamente fantasiosa, uma vez que as hipóteses de conciliar, transigir ou desistir nos processos da competência dos Juizados Especiais, ainda que previsto que sejam apenas nos termos e nas hipóteses previstas na lei do respectivo ente da Federação, são quase inexistentes.

Então, a decisão nestes processos se dará exclusivamente pelo magistrado, uma vez que é impossível a composição através da possibilidade de escolha da parte representada pelo Estado.

Indo mais além, e não menos importante, a competência no foro onde estiver instalado Juizado Especial da Fazenda Pública, é absoluta. Isto significa, que, independente da vontade 
das partes, somente poderá ajuizar ação neste Juizado. Não existe escolha, é obrigatório.

Outro ponto a se questionar é a dispensa do reexame necessário (art. 11 da Lei 12.153/2009). Esta prerrogativa existe pela natureza do bem tutelado e pela representação social que este tem.

Ora, é sabido que as decisões do Estado, além de administrativas, são políticas, não podendo os demais Poderes interferir, salvo se contrario a lei, ou realizados não obedecendo a finalidade pública, o interesse púbico, nem pode o Estado simplesmente dispor de algo que foi amplamente tratado pelos poderes legislativos e executivo.

Não se fala aqui em uma escolha ampla, sem critérios. O administrador não pode dispor de todas as opções que um particular dispõe. Dentro da legalidade, existe uma possibilidade de escolha com a finalidade única de se cegar ao interesse público. Ainda em situações onde o ato seja discricionário, importante observar o previsto em lei, além da obediência aos princípios da razoabilidade e proporcionalidade.

O Estado Constitucional, numa de suas expressivas dimensões, pode ser traduzido como o Estado das escolhas administrativas legítimas. Assim, considerado, nele não se admite a discricionariedade pura, infantil, sem limites. Em outras palavras, impõese controlar (ou ao menos mitigar) os contumazes vícios forjados pelo excesso degradante, pelos desvios ímprobos ou pela omissão desidiosa. (FREITAS, 2009, p. 10)

Não resta dúvida que pode, em casos de excessos e ilegalidades, os demais Poderes questionar as decisões administrativas. O Poder Judiciário, inclusive, pode, através do controle judicial destes atos, anulá-los. Porém não se pode, simplesmente, deixar de observar a lei quando da atuação administrativa.

Assim, pode sofrer este ato controle de legalidade, mas não se pode adentrar o mérito deste ato. Nem se pode fazer a opção pelo administrador, que tem autorização para decidir, uma vez que este é o seu papel. Se pode controlar se esta escolha é legal e se esta obedecendo os parâmetros razoáveis. Neste momento está-se diante do controle judicial dos atos administrativos.

A limitação do controle, pelo Poder Judiciário, dos atos administrativos, que tradicionalmente enfatizada como restrita à legitimidade ou à legalidade, e que ficava isento de controle os juízos de conveniência, oportunidade e eficiência do ato, ante a 
tendência de universalização da jurisdição, vem, hoje cedendo lugar a uma ampliação cada vez maior da atuação do Judiciário nesta questão. (PANCOTTI, 2008, pág. 135).

Apesar da Administração Pública esta diretamente ligada ao Poder Executivo, e ser normalmente contra este que se litiga nos Juizados Especiais da Fazenda Pública, resta importante assinalar que faz parte dela também os demais poderes. Assim, deve obedecer estes os princípios constitucionais referentes a administração pública, bem como garantir o interesse público.

\footnotetext{
Além disso, é o Poder Judiciário quem faz o controle judicial dos atos administrativos sendo, desse modo, embora de forma indireta, também um defensor e, portanto, representante dos interesses públicos, lutando para que se tenha um respeito irrestrito à Constituição. (BEZERRA, 2008, p. 57).
}

Muitas vezes, a priori, se percebe que o controle judicial alcança o mérito administrativo, a discricionariedade. Mas isto só ocorre quando se observa que a legalidade não foi respeitada, casos estes que se analisa o principio da razoabilidade de maneira mais precisa.

Em todo caso, o Judiciário tem a autorização para discutir e anular tal ato administrativo eivado de vicio, sendo perfeitamente possível a analise dos princípios administrativos constitucionais, tanto os expressos no art. 37, CRFB, quanto os implícitos. Aqui encontra-se a limitação não apenas do judiciário, mas também da Fazenda Pública para qualquer conciliação.

Observando estes pontos relevantes, verificam-se situações especiais que precisam de atenção, principalmente por sua incompatibilidade com os princípios administrativos trazidos no boja na Constituição da República.

Compreendendo os princípios e objetivos dos Juizados Especiais, e conhecendo os princípios e prerrogativas da Fazenda Pública, resta claro que existe uma incompatibilidade entre estes dois institutos.

A Fazenda Pública não pode transigir, ela não pode dispor. Porem, ela pode, de maneira coletivizada, atender os anseios sociais. Porque o direito não existe senão pela sociedade (BEZERRA, 2008, p. 45), e ele deve coexistir em toda estrutura estatal.

Portanto, se ela, em um caso concreto, dentro de uma lide, transige com um individuo, deveria estender erga omines esta decisão, sob pena de privilegiar um individuo, indo de encontro com o principio da impessoalidade.

O Estado não pode administrar pra um ou outro, mas para toda a coletividade 
(RAMOS, 2012). Tem como função a integração social e a realização da igualdade, ou melhor, isonomia. Assim, justamente para atender a isonomia, necessário uma política discriminatória, mas não feita pensando em uma pessoa em especial, mas um grupo indefinido. Se o Estado tem como função gerir o interesse da coletividade, não pode utilizar de seus recursos para beneficiar uma pessoa em especial, sendo sempre suas ações despersonalizadas.

Por outro lado, importante analisar este principio pela perspectiva também de quem o representa. Os seus agentes públicos, quando em suas funções públicas, representam o Estado, portanto agem em seu nome, não em nome próprio. Esse afastamento é importante para se atingir o ideal de coletividade, numa dimensão menos pessoal da Administração Pública.

A transação este ambiente é impossibilitada. Não existe compatibilidade entre os princípios administrativos e os princípios trazidos nos Juizados da Fazenda Pública, se não a tentativa de celeridade, deixando de lado prerrogativas e o próprio acesso a justiça que é mitigada por uma falsa sensação de justiça por causa da judicialidade.

Justiça não é sinônimo de judicial. Levar uma lide ao judiciário não significa resolução de caso de forma justa. Ate deveria ser, mas não é. Principalmente se para tanto os princípios constitucionais forem sacrificados. Justiça não tem um órgão ou poder que a guarde, ela é reflexo dos anseios sociais.

E a concepção da justiça que dela resulta tem uma certa primazia reguladora em relação aos princípios e aos critérios que são apropriados em outros casos. Entendese como estrutura básica a maneira pela qual as principais instituições sociais se arranjam em um sistema único, pelo qual consignam direitos e deveres fundamentais e estruturam a distribuição de vantagens resultante da cooperação social. (RAWLS, 2002, p. 03)

Portanto, ter um poder ou um ente que cuide da ordem jurídica do país não traduz a efetivação da justiça, nem a garantia que se tenha um sistema jurisdicional justo. Perpassa a intencionalidade dos órgãos e a utilização coerente de suas competências. Apesar de bons profissionais atuando nos Juizados Especiais da Fazenda Pública, a estrutura destes órgãos afasta a concepção de justiça e questiona a própria funcionalidade do acesso a ela.

O acesso a justiça não se traduz num acesso ao judiciário, mas a uma estrutura estatal que trabalhe em prol da justiça. Parte de todos os órgãos e poderes, sendo o poder judiciário órgão que detém a função precípua de julgar conforme os ditames legais (lei enquanto sinônimo de norma). 
O Poder Judiciário teria a função de garantir e defender os direitos individuais, com a clara intenção de promover a esperada justiça. A divisão calculada das funções/poderes não encontra mais espaço nos dias de hoje. Ainda existe uma necessidade de uma divisão de poder/dever, mas não de maneira tão absoluta e pragmática.

A separação absoluta entre os Poderes não é só impossível - haja vista a unidade do
Poder político e a tarefa comum a todos - mas também indesejada, de tal modo que
distante de uma separação de Poderes, o que se tem, deveras, é uma
verdadeira coordenação ou colaboração ou co-participação entre os Poderes em
certas tarefas, onde um Poder participa, de forma limitada e secundária, da função de
outro, que a conserva sua, ensejando um funcionamento harmônico ou uma
colaboração recíproca, embora independente, na tarefa comum, tendo como objetivo
o equilíbrio político, a limitação do Poder e, em conseqüência, a proteção da liberdade
e a melhor realização do bem comum. (CUNHA JUNIOR, 2015)

Da mesma forma que não se pode ver a justiça por uma única ótica, não se pode ver o direito da mesma maneira. Hoje, não mais se entende o direito como algo estanque, rígido, mas como uma ordem permeável aos valores e aos fatos da realidade cambiante (SOARES, 2010, p. 62). Isso tudo reflete a dinamicidade do direito, que acompanha as alterações sociais de maneira instantânea, compreendendo como um direito mais flexível.

Esta flexibilidade não esta presente apenas no judiciário, mas como ele é o realizador da "justiça", mais visivelmente se observa nele. Mesmo porque o elemento normativo não deixou de existir, pelo contrário, mas ele não é a única fonte. Mais, a norma sempre tratada e relacionada com os ditames constitucionais.

Então, numa situação onde o Estado não é garantidor de direitos, resta ao cidadão a busca destes através do poder judiciário. Aqui se traduz um principio fundamental basilar para a discussão da funcionalidade dos Juizados da Fazenda Publica, qual seja, o principio do acesso a justiça.

O princípio fundamental do acesso à justiça não se esgota apenas na possibilidade de se ter tutela jurisdicional. Conforme lições de Wilson Alves da Silva "se é indispensável a porta de entrada, necessário igualmente é que exista a porta de saída” (SOUZA, 2011, p. 26), ou seja, necessários os meios de garantir um acesso a justiça devido, justo, com observância do contraditório, ampla defesa, tempo razoável, entre outros.

Portanto, o acesso à justiça deve ser observado em sua perspectiva global. Não apenas se fala do acesso à justiça formal, mas também do acesso a justiça material. Mais que isto, trata- 
se de perceber se de fato é conseguido dentro das perspectivas de razoabilidade, proporcionalidade, até mesmo de justiça.

Perceber o acesso à justiça dentro dos Juizados Especiais de Fazenda Pública é perceber se efetiva ou não e não apenas relacionar a sua importância pela duração do processo. A duração razoável do processo é apenas uma das características do acesso à justiça, que precisa ser observado, mas não é o acesso à justiça em si mesmo.

Estes aspectos iniciais dão o tom da discussão que se pretende traçar, uma vez que o papel Poder Judiciário vai além de um simples resultado e o acesso à justiça é muito mais amplo que apenas se ter uma decisão.

A compreensão destas premissas deve ser feita quando diante de qualquer procedimento, incluindo os previstos nos Juizados Especiais de Fazenda Pública. Então, não basta aplicar a celeridade previstas nesta instancia sem verificar se as regras permitem ou não a real analise da tutela devida. O respeito ao direito administrativo e as nuances deste direito devem ser analisadas dentro deste processo.

\section{CONCLUSÃO}

A utilização de meios para facilitar o acesso à justiça e aproximar o direito das diversas camadas sociais é uma necessidade constante do Estado. Principalmente em uma sociedade onde a desigualdade social é realidade. Aproximar os Estado e seus diversos poderes dos cidadãos, mais que uma obrigação, seria, talvez, a única forma de cidadania.

A verificação de crescentes demandas em face da Fazenda Pública e o abarrotamento das Varas de Fazenda Pública com milhares de causas pede providencias a fim de facilitar o acesso a justiça, buscando meios para a concretização da tutela jurisdicional. A criação dos Juizados da Fazenda Pública pretende este fim.

Ocorre que, com a motivação precisa esta em consonância com os princípios e as finalidades do que se tutela, correndo o risco de não efetivar o pretendido em sua criação: o acesso a justiça facilitado com uma resposta rápida às tutelas ali tratadas.

A aplicação das regras constantes na Lei n 12.153/2009 não atendem as especificações referentes à Fazenda Pública e acabam por comprometer a eficácia na prestação jurisdicional que passa a ter impacto não apenas entre as partes, mas conseqüências para toda uma coletividade.

A regra dos juizados é a conciliação e a Administração Pública não pode conciliar. Isto 
acontece porque ele tem como principio básico, como já explanado, a legalidade estrita. Não pode abrir mão da lei. Tem que cumpri-la. Então, num caso concreto, não pode simplesmente se escusar do cumprimento da norma legal, ainda que mais vantajosa no caso concreto.

Também deve observar o principio da impessoalidade, ou seja, não pode ter tratamento diferenciado entre seus administrados. A transação encontra barreira também neste ponto, sendo impossível o cumprimento desta prerrogativa dos Juizados Especiais.

Por ter sua competência absoluta, os Juizados Especiais da Fazenda Pública acabam tendo milhares de demandas que terão rapidez na sua sinalização, mas não cumprirá os requisitos fundamentais relacionados ao acesso a justiça material.

A celeridade é requisito fundamental para o acesso a justiça, mas não é o único. A justiça precisa ser observada tendo o devido processo legal, contraditório e ampla defesa como pressupostos indispensáveis. Também a consciência e o conhecimentos nos princípios constitucionais que limitam a atuação estatal, protegendo com isto toda a coletividade.

O Estado democrático de direito pede cada vez mais uma relação comunicativa não só entre suas instituições, mas também com a sociedade. Tanto que existe uma inclinação para a compreensão dos mecanismos hermenêuticos que traduzem as relações sociais, incluindo, por obvio, o próprio direito, que passa a ser percebido na transdisciplinaridade. Não se pode falar mais de imposição do Governante como se a sociedade representasse seus súditos e ele o rei. A realidade foi alterada e hoje a cobrança e participação social é inevitável.

A partir de uma democracia participativa, o discurso passa a ser um elemento importante. Isto é vislumbrado no direito à petição, no acesso aos órgãos públicos e judiciário, nas possibilidades de intervenção política e participação popular.

Surge disto a chamada Administração Pública Dialógica, que apresenta mecanismos e espaços de participação social. As decisões administrativas, assim como as construções conceituais são o resultado de um processo dialógico com o cidadão, de maneira individualizada ou coletivizada.

Mas não se deixa de aplicar com isto os princípios constitucionais da impessoalidade e legalidade, pelo contrário. A observação da coisa pública como de todos faz com que estes princípios sejam cada vez mais importantes e devam permanecer na busca de situações de paridade.

Pretendendo apenas tratar de questões de baixa complexidade, a criação destes juizados aparece como falácia uma vez que não existe pouca complexidade numa lide que envolva a Administração Pública, pelo contrário. Estas lides envolvem impacto orçamentário, 
aplicação da Constituição Federal, alteração no quadro de servidores, dentre outras coisas. Não há como transigir em situações como estas, não enquanto ente público.

Obvio que esta impossibilidade de escolha afasta qualquer tipo de composição que não seja absolutamente prevista em lei. Então, a analise jurisdicional sobre os litígios envolvendo a Fazenda Pública são muito mais legalistas, necessitando de uma análise da lei e não vontade das partes.

Se não existe vontade por parte da Administração Pública, não pode esta dizer se deixa ou não de cumpria a lei, se pode ou não abrir qualquer tipo de exceção. Então esta regra - da obrigatoriedade da audiência de conciliação - se torna uma imposição sem sentido e absolutamente inócua, afastando o real sentido da tutela jurisdicional.

Portanto, percebe-se logo de pronto que o formato dos Juizados de Fazenda Pública não é adequado as necessidades deste tipo de litígio, o que afasta a efetividade do acesso a justiça, afastando este direito fundamental. Percebe-se, então, que os Juizados de Fazenda Pública, como estão apresentados hoje, não cumprem sua função, indo de encontro ao real princípio do acesso à justiça.

\section{REFERENCIAS}

ALEXY, Robert. Teoria dos Direitos Fundamentais. São Paulo: Malheiros Editores, 2008. BEZERRA, Paulo Cesar Santos. A Produção do Direito no Brasil. Ilheus: Editora da UESC, 2008.

BEZERRA, Paulo Cesar Santos, Acesso à Justiça: um problema ético-social no plano da realização do direito. Rio de Janeiro: Renovar, 2008.

BOBBIO, Norberto. Teoria geral do direito. São Paulo: Martins Fontes, 2008.

BRASIL. Constituição (1988). Constituição da República Federativa do Brasil de 1988. Disponível em: <http://www.planalto.gov.br/ccivil_03/constituicao/constituicao.htm>. Acesso em 08 abr. 2018. 
. LEI No 9.099, DE 26 DE SETEMBRO DE 1995. DisPÕE SOBRE OS JUIZADOS ESPECIAIS

CívEIS E CRIMINAIS E DÁ OUTRAS PROVIDÊNCIAS. DisPONÍVEL EM: < HTTP://WWW.PLANALTO.GOV.BR/CCIVIL_03/LEIS/L9099.HTM>. ACESSO EM 03 DE FEV. 2018.

. LEI No 9.099, de 26 DE SETEMBRo de 1995 - EXPOSIÇÃo DE MOTIVOS. DisPONÍVEL

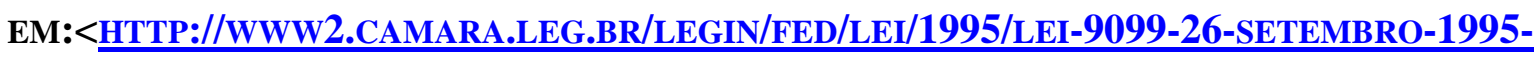
348608-EXPOSICAODEMOTIVOS-149770-PL.HTML >. ACESSO EM 23 DE MAR. 2018.

. LEI No 12. 153, DE 22 DE DEZEMBRO DE 2009. DISPÕE SOBRE OS JUIZADOS ESPECIAIS DA FAzenda Pública no ÂMBito dos Estados, Do Distrito FEDERAL, DOS TERRITóRios E DOS MunicíPIOS. DisPonível EM < HTTP://WWW.PLANALTO.GOV.BR/CCIVIL_03/_ATO20072010/2009/LEI/L12153.HTM>. ACESSO EM 23 DE MAR. 2018.

CANOTILHO, JJ Gomes. Direito Constitucional e Teoria da Constituição. 7. Ed. Coimbra: Almedina, 2003.

CORREA, Leonardo Alves; LUZ SEGUNDO, Elpidio Paiva. O Princípio da Eficiência: Interlocução entre a Gestão Pública Ampliada e o Novo Paradigma da Administração Pública Dialógica à Luz do Estado Democrático de Direito. Disponível em: <http://www.conpedi.org.br/anais/36/05_1689.pdf>. Acesso em 01 de dez. 2014.

CUNHA JUNIOR, DIRLEY DA. ATIVISMO JUDICIAL E CONCRETIZAÇÃO DOS DIREITOS FUNDAMENTAIS. DISPONÍVEL EM:

HTTPS://BRASILJURIDICO.COM.BR/ARTIGOS/ATIVISMO-JUDICIAL-ECONCRETIZACAO-DOS-DIREITOS-FUNDAMENTAIS.-POR-DIRLEY-DA-CUNHA-

JUNIOR.>. ACESSO EM 23 DE MAR. 2018.

FAGUNDEZ, Paulo Roney Ávila. Os novos direitos à luz da transdisciplinaridade: o resgate de um humanismo radical e a promoção da ecologia na sociedade do mal-estar. Espaço Jurídico, Joaçaba, v. 9, n. 1, p. 57-66, jan./jun. 2008.

FREITAS, Juarez. Discricionariedade Administrativa e o Direito Fundamental à Boa Administração Pública. São Paulo: Malheiros Editores, 2009.

GEERTZ, Clifford. A Interpretação Das Culturas. Rio de Janeiro: LTC, 2008.

HABERMAS, Jurgen. A Inclusão do Outro: estudos da teoria política. São Paulo: Edições Loyola, 2002.

HABERMAS, Jungen. Direito e Democracia - entre a facticidade e a validade Vol. II. Rio de Janeiro: Tempo Brasileiro, 1997. 
MELLO, Celso Antonio Bandeira. Curso de Direito Administrativo. São Paulo: Malheiros, 2006.

NETTO, Luisa Cristina Pinto e. O Princípio de Proibição de Retrocesso Social. Porto Alegre: Livraria do Advogado, 2010.

PANCOTTI, José Antonio. Inafastabilidade da Jurisdição e o Controle Judicial da Discricionariedade Administrativa. São Paulo: LTR Editora, 2008.

RAMOS, Gisela Godin. Princípios Jurídicos. Belo Horizonte: Fórum, 2012.

RAWLS, John. Justiça e Democracia. São Paulo: Martins Fontes, 2002.

ROCHA, Carmen Lúcia Antunes. Princípios Constitucionais da Administração Pública. Belo Horizonte: Editora Del Rey, 1994.

ROUSSEAU, Jean-Jacques. O Contrato Social. São Paulo: Martins Fontes, 1996.

SILVA, Jose Afonso da. Comentário Contextual à Constituição. São Paulo: Malheiros, 2008. SOARES, Gabriela Mansur. Administração Pública Dialógica Na Constituição De 1988: A Construção do Interesse Público com a Participação da Sociedade Civil. Disponível em: $<$ http://www.conpedi.org.br/manaus/arquivos/anais/brasilia/07_823.pdf $>$. Acesso em 02 de dez. 2014.

SOARES, Ricardo Mauricio Freire. O Principio Constitucional da Dignidade da Pessoa Humana - em busca do direito justo. São Paulo: Saraiva, 2010.

SOUZA, Wilson Alves de. Acesso à Justiça. Salvador: Editora Dois de Julho, 2011.

VILANI, Maria Cristina Seixas. Cidadania moderna: fundamentos doutrinários e desdobramentos históricos. Caderno de Ciências Sociais, Belo Horizonte, 2002. 